Gut, 1972, 13, 58-63

\title{
The effect of portacaval anastomosis on oral carbohydrate tolerance and on plasma insulin levels
}

\author{
C. D. HOLDSWORTH ${ }^{1}$, LYNNE NYE, AND ELIZABETH KING
}

From the Departments of Medicine, Gastroenterology, and Chemical Pathology, St Bartholomew's Hospital, London, and St Leonard's Hospital, London

SUMMARY In patients with portal hypertension, plasma insulin levels were raised both fasting and after oral glucose or intravenous tolbutamide. This supports previous suggestions that resistance to endogenous insulin plays a major role in producing the impaired glucose tolerance found in chronic hepatic dysfunction.

The operation of portacaval anastomosis was followed by impaired oral fructose tolerance, but did not significantly change oral glucose tolerance. Plasma insulin levels were unchanged by the operation, either fasting orfollowing the stimulus of an oral glucoseload or intravenous tolbutamide. The insulin response after operation was only higher after intensive pancreatic $\beta$ cell stimulation by a combination of glucose, tolbutamide, and glucagon. These results indicate that, in patients with hepatic dysfunction, little insulin is being removed by the liver from the portal blood except when the insulin secretory rate is unusually high.

Normally all carbohydrate from the intestine and insulin from the pancreas passes through the liver before reaching the systemic circulation. After the operation of portacaval anastomosis (Fig. 1) changes in carbohydrate metabolism might be expected because the liver has been bypassed. No systematic studies have been undertaken to investigate this possibility and the few clinical reports provide contradictory evidence. Thus the occasional development of diabetes mellitus has been noted whereas in other patients preexisting diabetes has been found to improve after the operation (Hearn and Paton, 1963). Another study of interest in this context is that of Megyesi, Samols, and Marks (1967) who performed oral glucose tolerance tests on four patients with portacaval anastomoses. They obtained similar blood sugar responses to those found in patients with untreated cirrhosis, but the rise of plasma insulin was unusually high. They pointed out that the latter finding was consistent with the claim that $20-50 \%$ of the insulin secreted by the pancreas is removed during its initial transhepatic passage (Samols and Ryder, 1961), thus reducing the amount of insulin reaching the systemic circulation.

'Present address: The Royal Infirmary, Sheffield S6 3DA.

Received for publication 22 September 1971.

\section{BEFORE OPERATION}

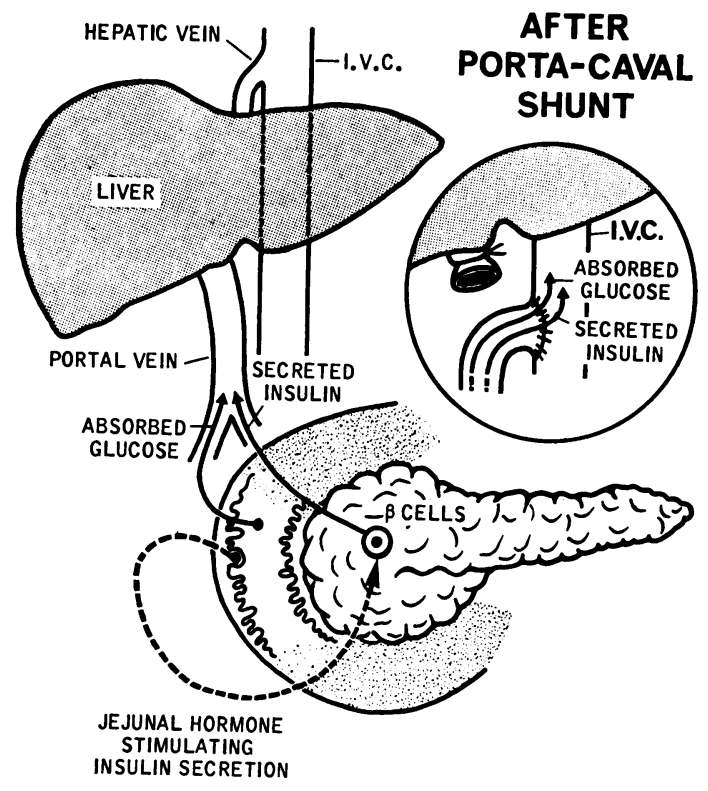

Fig. 1 The anatomical changes which may affect carbohydrate metabolism after portacaval anastomosis. 
In the present investigation patients have been studied both before and after portacaval anastomoses, using glucose, fructose, tolbutamide, and a combination of glucagon, tolbutamide, and glucose.

\section{Patients and Methods}

A total of 11 patients were investigated all of whom had portal hypertension. They had previously bled at least once from oesophageal varices and were shown at operation to have a patent portal vein. Each patient was studied before and again three to four weeks after an end-to-side portacaval anastomosis had been performed. The tests were carried out at a time when they were ambulant and taking a diet liberal in carbohydrate. All blood samples were taken using an indwelling cannula inserted in a forearm vein.

One group of six patients was studied by means of oral fructose and glucose tolerance tests. Three of these patients had cirrhosis, the aetiology being alcoholic in two and cryptogenic in the third; they had impaired hepatic cellular function causing episodes of precoma. Three patients had less evidence of hepatocellular damage. Two of these were jaundiced, the diagnosis being cryptogenic macronodular cirrhosis with cholestatic features, and the third patient had non-cirrhotic intrahepatic portal hypertension (Zeegen, Stansfeld, Dawson, and Hunt, 1970). The tolerance tests were performed in the conventional manner, with blood samples being

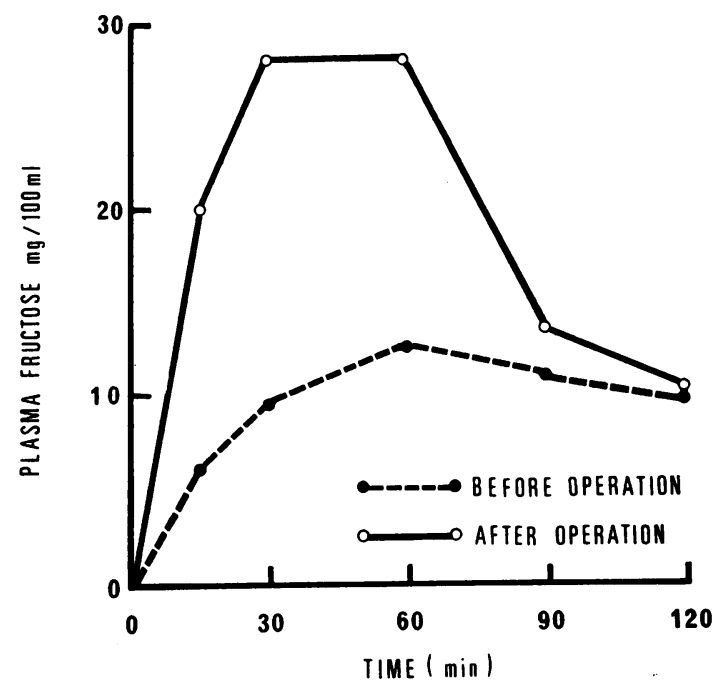

Fig. 2a

Fig. 2 Mean plasma fructose levels after $50 \mathrm{~g}$ of oral fructose: (a) in three patients with good preoperative liver function: (b) in three patients with more impaired preoperative liver function. taken fasting and subsequently at regular intervals following the ingestion of fructose or glucose.

The second group comprised five patients with cirrhosis of whom three were alcoholic and two cryptogenic in origin. Blood glucose and insulin levels were determined before and at intervals after the intravenous administration of $1 \mathrm{~g}$ of tolbutamide and, on separate occasions, during a 'maximum' stimulation test (Ryan, Nibbe, and Schwartz, 1967). This involved the oral administration of $50 \mathrm{~g}$ of glucose followed after $\mathbf{3 0}$ minutes by the intravenous injection, over the course of one minute, of $0.5 \mathrm{~g}$ of tolbutamide and $1 \mathrm{mg}$ of glucagon.

Glucose levels were determined by a specific glucose oxidase technique (Huggett and Nixon, 1957) and fructose by a colorimetric procedure (Zender and Falbriard, 1966). Plasma levels of immunoreactive insulin were determined by radioimmunoassay, employing dextran-coated charcoal to separate the bound and free fractions (Herbert, Lau, Gottlieb, and Bleicher, 1965). The significance of changes in blood glucose and plasma insulin was assessed by means of a paired $t$ test.

\section{Results}

FRUCTOSE TOLERANCE TESTS

In the three patients with relatively good preoperative liver function mean blood fructose levels were higher throughout the tests after operation (Figure 2a). The mean maximum rise after operation

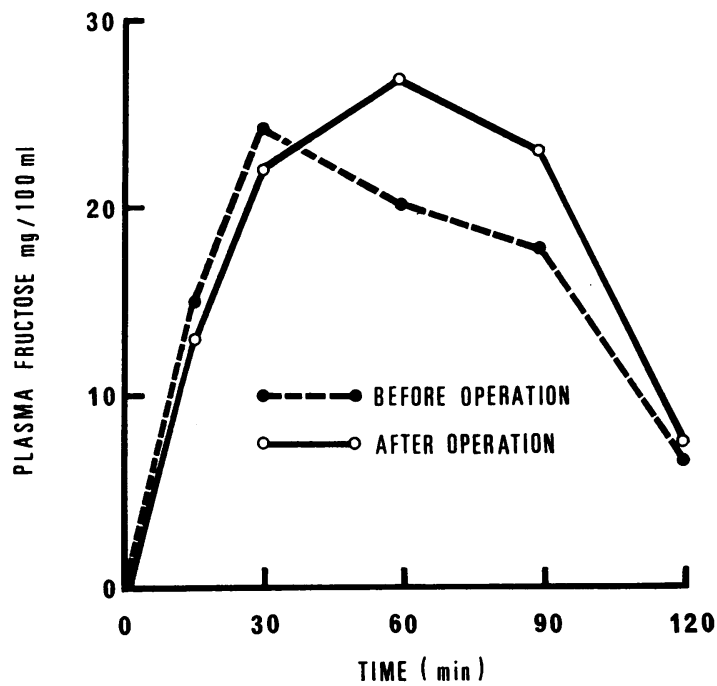

Fig. 2b 
was $30.0 \mathrm{mg} / 100 \mathrm{ml}$, which is significantly greater than that before operation, which was $15.7 \mathrm{mg} / 100$ $\mathrm{ml}(\mathrm{P}<0.05)$. In the other three patients fructose tolerance did not change after operation (Figure 2b). This can be attributed to their clearly abnormal fructose tolerance before surgery, and is consistent with the fact that they had poorer liver function by other criteria. We have found comparable abnormalities of fructose tolerance in many patients with severely impaired hepatic function due either to cirrhosis or to viral hepatitis (unpublished observations).

ORAL GLUCOSE TOLERANCE TESTS

In the same six patients, after oral glucose, neither the individual nor the mean glucose and insulin levels were affected by portacaval anastomosis
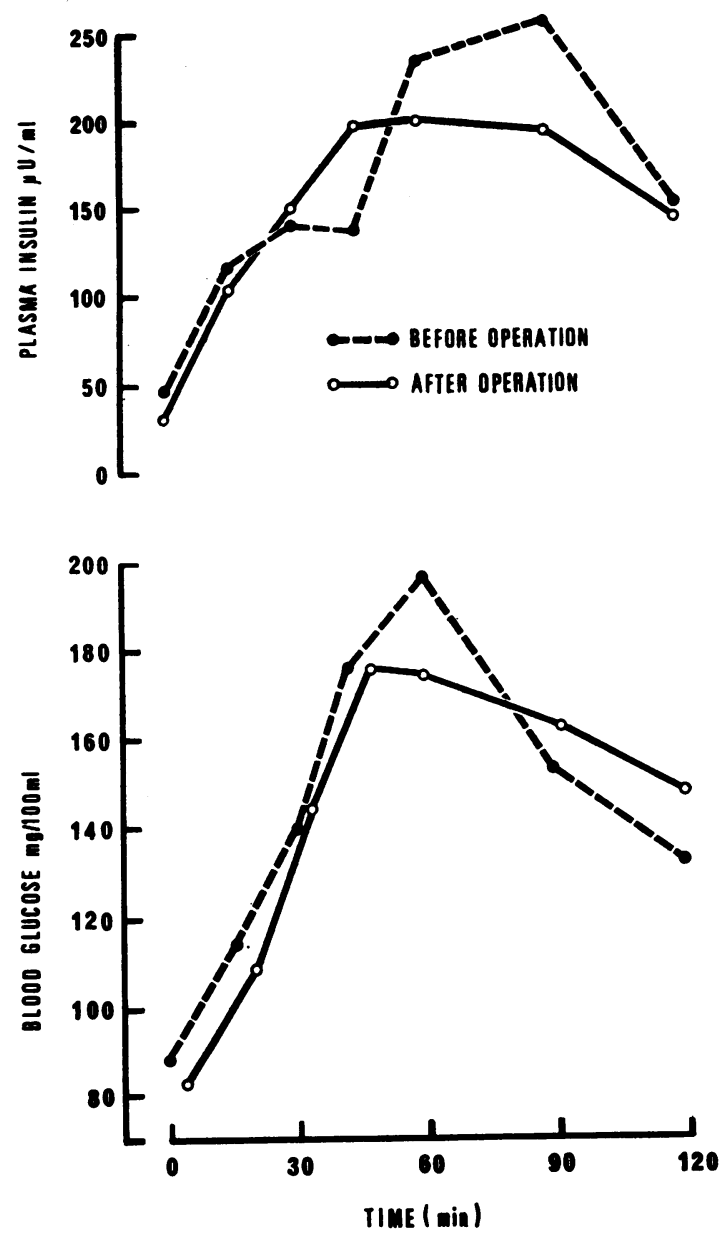

Fig. 3 Mean plasma insulin and blood glucose levels after $50 \mathrm{~g}$ of oral glucose.
(Figure 3). The rise in plasma insulin (dI), compared with the rise in blood glucose (dG), expressed as a ratio dI/dG (Seltzer, Allen, Herron, and Brennan, 1967) for nine patients (including three patients who had a glucose, glucagon, tolbutamide test) at 15 and 30 minutes after oral glucose was not significantly different after operation. At 15 minutes the ratio was $2.0 \pm 0.66(\mathrm{M} \pm \mathrm{SE})$ before, and $1.71 \pm 0.63$ after, operation, and at 30 minutes $2.0 \pm 0.56$ before, and $2 \cdot 1 \pm 0.54$ after, operation.

\section{INTRAVENOUS TOLBUTAMIDE TESTS}

The results of intravenous tolbutamide tests before and after surgery in the second group of five patients are shown in Figure 4. There was no significant difference in either the fall of blood sugar or rise of insulin. Although there was a tendency for plasma
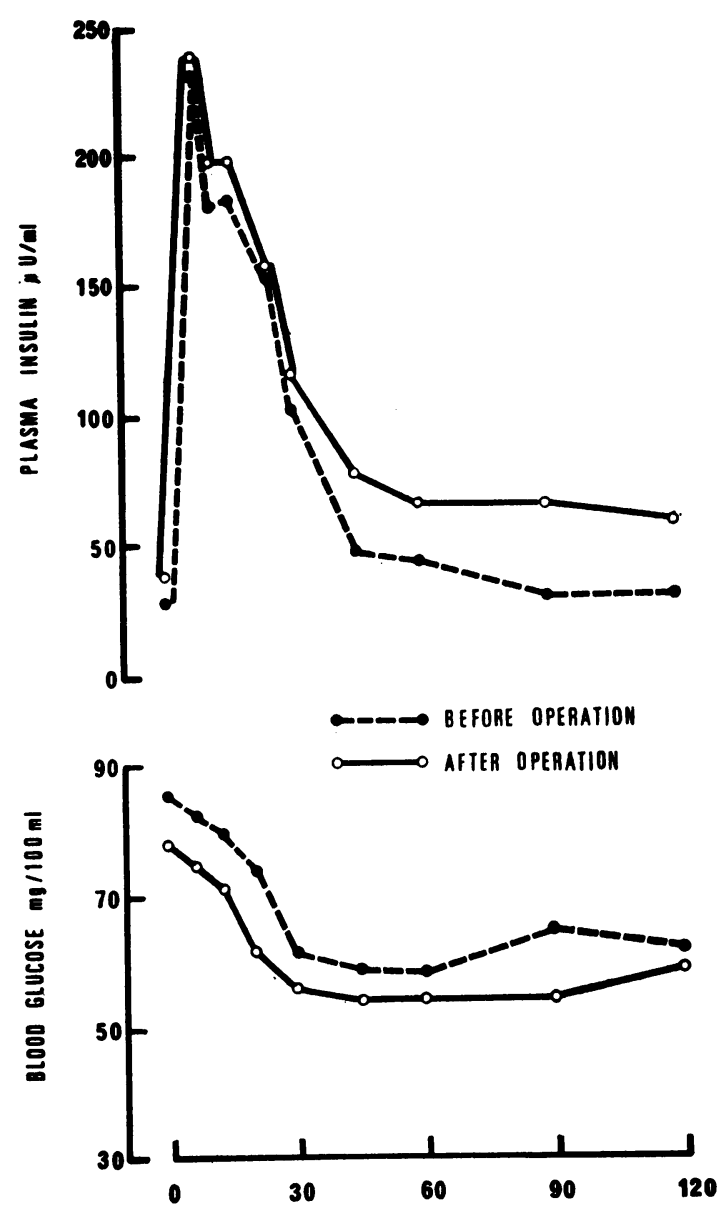

Fig. 4 Mean plasma insulin and blood glucose levels after $1 \mathrm{~g}$ of tolbutamide intravenously. 

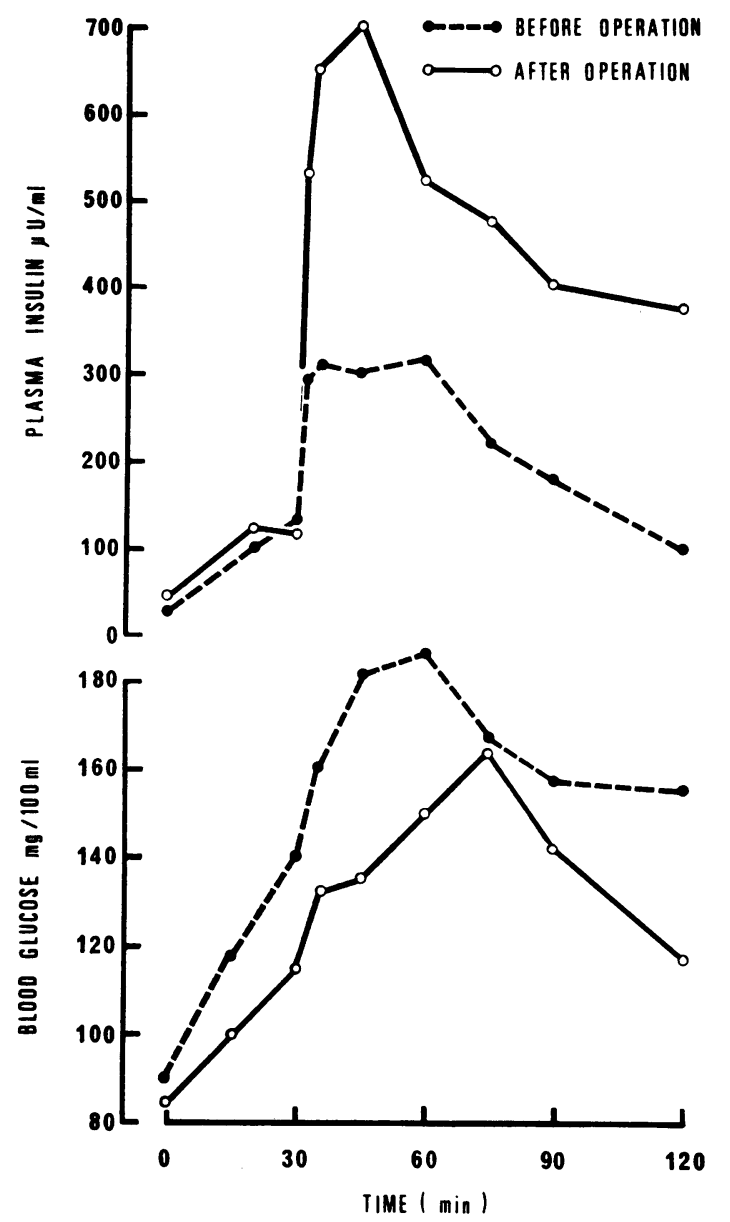

Fig. 5 Mean plasma insulin and blood glucose levels after $50 \mathrm{~g}$ of oral glucose, followed after 30 minutes by $0.5 \mathrm{~g}$ of tolbutamide and $1 \mathrm{mg}$ of glucagon intravenously.

insulin levels to fall more slowly after operation, this was not statistically significant.

\section{GLUCOSE/GLUCAGON/TOLBUTAMIDE TESTS}

The combined stimulus resulted in very high levels of plasma insulin (Fig. 5), with the mean peak being significantly greater after operation $(P<0.001)$.
The mean rise in blood glucose was greater before operation, due largely to an unusual response by one patient, and was not statistically significant.

\section{RESPONSE TO EACH TYPE OF STIMULUS}

Hypersecretion of insulin in response to each type of stimulus was observed in most patients. In any one patient, hyper- or hyposection of insulin, in response to one stimulus, was associated with a similar response to the other stimuli, and examples of this are shown in Table $I$.

\section{Discussion}

The change in fructose tolerance which occurs after portacaval anastomosis in patients with relatively good liver function indicates that in man an appreciable proportion of an orally administered fructose load is removed by the liver. In patients with markedly impaired hepatic function the test is abnormal before operation, so that interpretation of individual postoperative fructose tolerance tests may be difficult. Therefore it cannot be used, as has been suggested (Martin and Bryant, 1962), as a simple clinical test for the patency of portacaval anastomoses.

The glucose and insulin response to an oral glucose load did not change after operation and the expectation, on anatomical grounds (Fig. 1), that blood glucose and plasma insulin levels might be higher after surgery was not fulfilled. Similarly after intravenous tolbutamide, plasma insulin levels were unaffected by diversion of portal blood. By contrast the more prolonged rise in plasma insulin levels, caused by the combined stimulus of glucose, glucagon, and tolbutamide, was more marked after operation.

The present results, with respect to glucose, are in accordance with previous findings (McIntyre, Turner, and Holdsworth, 1970) that, in dogs, peripheral blood glucose levels are similar after glucose infusions into either the portal or an arm vein, but our observations on insulin levels are difficult to reconcile with previous claims that the liver removes much secreted insulin before it reaches the systemic circulation (Samols and Ryder, 1961). While it is unwise to generalize about the role of the normal

\begin{tabular}{|c|c|c|c|c|c|c|c|c|}
\hline & \multicolumn{8}{|c|}{ Plasma Insulin Response ( $\mu U$ per $m l)$} \\
\hline & \multicolumn{2}{|l|}{ Fasting } & \multicolumn{2}{|c|}{30 Minutes after Glucose } & \multicolumn{2}{|l|}{$\begin{array}{l}\text { Intravenous } \\
\text { Tolbutamide }\end{array}$} & \multicolumn{2}{|c|}{$\begin{array}{l}\text { Glucose/Glucagon/ } \\
\text { Tolbutamide }\end{array}$} \\
\hline & Preoperative & Postoperative & Preoperative & Postoperative & Preoperative & Postoperative & Preoperative & Postoperative \\
\hline $\begin{array}{l}\text { 'High responder' } \\
\text { 'Low responder' }\end{array}$ & $\begin{array}{l}30 \\
25\end{array}$ & $\begin{array}{l}40 \\
30\end{array}$ & $\begin{array}{r}280 \\
60\end{array}$ & $\begin{array}{r}130 \\
60\end{array}$ & $\begin{array}{r}350 \\
75\end{array}$ & $\begin{array}{l}235 \\
115\end{array}$ & $\begin{array}{l}565 \\
145\end{array}$ & $\begin{array}{r}1,000 \\
160\end{array}$ \\
\hline
\end{tabular}

Table I Plasma insulin response $(\mu U$ per $\mathrm{ml})$ to three different types of stimulus before and after portacaval anastomosis in the two patients with highest and lowest insulin response 
liver from observations on patients with liver disease, it may be noted that similar results were obtained in three patients with relatively good liver function. In these patients diversion of portal blood resulted in impaired fructose metabolism but there was no significant change in plasma insulin levels following oral glucose or intravenous tolbutamide. However, the more marked increase in plasma insulin levels following oral glucose, glucagon, and tolbutamide after operation suggests that the liver may remove secreted insulin from the blood when portal vein insulin levels are very high. This conclusion has also been reached as a result of experiments in dogs (Waddell and Sussman, 1967).

An additional factor which could affect insulin response after diversion of portal blood is the glacagon-like hormone released by the mucosa of the small intestine after oral glucose (McIntyre, Holdsworth, and Turner, 1965) (Fig. 1) which stimulates insulin release, since this substance may also be removed by the liver (Buchanan, Solomon, Vance, Porter, and Williams, 1968). Our results suggest that hepatic removal of intestinal factors which stimulate insulin secretion is likely to be of only minor importance.

The fall in blood glucose following intravenous tolbutamide was very similar after operation to that seen before operation. This suggests that the hypoglycaemic effect of insulin is the same, whether it passes through the liver first or is secreted directly into the systemic circulation. Similar conclusions have been reached from dog experiments, which showed a similar hypoglycaemic response, following intraportal or systemic injection of insulin (Madison and Unger, 1958; Starzl, Scanlan, Yanof, Thornton, Wendel, Stearn, Lazarus, McAllister, and Shoemaker, 1963).

In patients with cirrhosis of the liver the abnormal pattern of carbohydrate metabolism has been compared with that of maturity onset diabetes and obesity, as impaired glucose tolerance and endogenous and exogenous insulin resistance are found in both conditions (Megyesi, Samols, and Marks, 1967; Samols and Holdsworth, 1968) but the normal insulin increment $\mathrm{dI} / \mathrm{dG}$ in our patients is unlike diabetes (Seltzer et al, 1967), and suggests obesity as the closer analogue. The high plasma insulin levels found both fasting and after oral glucose have been attributed in part to portal systemic shunting of blood and in part to an increased islet cell response, due to endogenous insulin resistance (Megyesi et al, 1967). Our observations suggest that the increased islet cell response is the more important factor. In contrast to Samols and Turner (1968), who did not study the same patients before and after portacaval shunts, we did not find a higher plasma insulin response to tolbutamide after operation, but we agree with these authors that patients with hepatic cirrhosis show a supranormal rise in plasma insulin after intravenous tolbutamide. The islet cells of patients with hepatic cirrhosis, again rather as in obesity (Perley and Kipnis, 1967), appear to hyperreact to a variety of insulinogenic stimuli and the degree of response in any one patient is roughly the same for each type of stimulus (Table I), probably reflecting varying degrees of islet cell hyperplasia.

We are grateful to our subjects for their cooperation, to the late $\mathrm{Mr} \mathrm{A}$. H. Hunt for his interest and for permission to study his patients, and to Professor J. Landon for guidance on the insulin immunoassay. The work was supported by a research grant from the North East Metropolitan Regional Hospital Board.

\section{References}

Buchanan, K. D., Solomon, S. S., Vance, J. E., Porter, H. P., and Williams, R. H. (1968). Glucagon clearance by the isolated perfused rat liver. Proc. Soc. exp. Biol. (N.Y.), 128, 620-623.

Hearn, G. W., and Paton, A. (1963). Development of diabetes mellitus after portacaval anastomosis. Brit. med. J., 2, 96-97.

Herbert, V., Lau, K. S., Gottlieb, C. W., and Bleicher, S. J. (1965). Coated charcoal immunoassay of insulin. J. clin. Endocr., 25, 1375-1384.

Huggett, A. St. G., and Nixon, D. A. (1957). Use of glucose oxidase, peroxidase and o-dianisidine in determination of blood and urinary glucose. Lancet, 2, 368-370.

Madison, L. L., and Unger, R. H. (1958). The physiologic significance of the secretion of endogenous insulin into the portal circulation. I. Comparison of the effects of glucagon free insulin administered via the portal vein and via a peripheral vein on the magnitude of hypoglycemia and peripheral glucose utilization. J. clin. Invest., 37, 631-639.

McIntyre, N., Holdsworth, C. D., and Turner, D. S. (1965). Intestinal factors in the control of insulin secretion. J. clin. Endocr., 25, 1317-1324.

McIntyre, N., Turner, D. S., and Holdsworth, C. D. (1970). The role of the portal circulation in glucose and fructose tolerance. Diabetologia, 6, 593-596.

Martin, L. W., and Bryant, L. R. (1962). The use of fructose to determine the patency of portal-systemic shunts. Arch. Surg., 85, 783-791.

Megyesi, C., Samols, E., and Marks, V. (1967). Glucose tolerance and diabetes in chronic liver disease. Lancet, 2, 1051-1056.

Perley, M. J., and Kipnis, D. M. (1967). Plasma insulin responses to oral and intravenous glucose: studies in normal and diabetic subjects. J. clin. Invest., 46, 1954-1962.

Ryan, W. G., Nibbe, A. F., and Schwartz, T. B. (1967). Beta-cytotrophic effects of glucose, glucagon and tolbutamide in man. Lancet, 1, 1255-1256.

Samols, E., and Holdsworth, C. D. (1968). Disturbances in carbohydrate metabolism, liver disease. In Carbohydrate Metabolism and its Disorders, Vol. 2, edited by F. Dickens, P. J. Randle, and W. J. Whelan, pp. 289-336. Academic Press, London.

Samols, E., and Turner, M. D. (1968). Unpublished observations quoted in Carbohydrate Metabolism and its Disorders, edited by F. Dickens, P. J. Randle, and W. J. Whelan, Vol. 2, p. 298. Academic Press, London and New York.

Samols, E., and Ryder, J. A. (1961). Studies of tissue uptake of insulin in man using a differential immunoassay for endogenous and exogenous insulin. J. clin. Invest., 40, 2092-2102.

Seltzer, H. S., Allen, E. W., Herron, A. L., Jr., and Brennan, M. T. Insulin secretion in response to glycemic stimulus: relation of delayed initial release to carbohydrate intolerance in mild diabetes mellitus. J. clin. Invest., 46, 323-335.

Starzl, T. E., Scanlan, W. A., Yanof, H. M., Thornton, F. H., Wendel, R. M., Stearn, B., Lazarus, R. E., McAllister, W., and 
Shoemaker, W. C. (1963). A comparison of the hypoglycemic effect of insulin with systemic venous and portal venous administration. J. surg. Res., 3, 293-300.

Waddell, W. R., and Sussman, K. E. (1967). Plasma insulin after diversion of portal and pancreatic venous blood to vena cava. J. appl. Physiol., 22, 808-812.

Zeegen, R., Stansfeld, A. G., Dawson, A. M., and Hunt, A. H. (1970)
Prolonged survival after portal decompression of patients with non-cirrhotic intrahepatic portal hypertension. Gut, 11, 610-617.

Zender, R., and Falbriard, A. (1966). Analyse colorimétrique des céto-heroses et de l'inuline par la réaction à, l'acide thiobarbiturique. Conditions de la réaction. Clin. chim. Acta, 13, 246-250. 